\title{
An EF hand mutation in Stim1 causes premature platelet activation and bleeding in mice
}

\author{
Johannes Grosse, ${ }^{1}$ Attila Braun, ${ }^{2}$ David Varga-Szabo, ${ }^{2}$ Niklas Beyersdorf, ${ }^{3}$ \\ Boris Schneider, ${ }^{1}$ Lutz Zeitlmann,, ${ }^{1}$ Petra Hanke, ${ }^{1}$ Patricia Schropp, ${ }^{1}$ Silke Mühlstedt, ${ }^{2}$ \\ Carolin Zorn, ${ }^{4}$ Michael Huber, ${ }^{4}$ Carolin Schmittwolf, ${ }^{1}$ Wolfgang Jagla, ${ }^{1}$ Philipp Yu, ${ }^{1}$ \\ Thomas Kerkau, ${ }^{3}$ Harald Schulze, ${ }^{5}$ Michael Nehls, ${ }^{1}$ and Bernhard Nieswandt ${ }^{2,6}$

\begin{abstract}
IIngenium Pharmaceuticals AG, Munich, Germany. ${ }^{2}$ Rudolf Virchow Center, DFG Research Center for Experimental Biomedicine, and 3Institute for Virology and Immunobiology, University of Würzburg, Würzburg, Germany.

${ }^{4}$ Max Planck Institute for Immunobiology, Freiburg, Germany. ${ }^{5}$ Laboratory for Pediatric Molecular Biology, Charité, Berlin, Germany. ${ }^{6}$ Institute of Clinical Biochemistry and Pathobiochemistry, University of Würzburg, Würzburg, Germany.
\end{abstract}

\begin{abstract}
Changes in cytoplasmic $\mathrm{Ca}^{2+}$ levels regulate a variety of fundamental cellular functions in virtually all cells. In nonexcitable cells, a major pathway of $\mathrm{Ca}^{2+}$ entry involves receptor-mediated depletion of intracellular $\mathrm{Ca}^{2+}$ stores followed by the activation of store-operated calcium channels in the plasma membrane. We have established a mouse line expressing an activating EF hand motif mutant of stromal interaction molecule 1 (Stim1), an ER receptor recently identified as the $\mathrm{Ca}^{2+}$ sensor responsible for activation of $\mathrm{Ca}^{2+}$ releaseactivated (CRAC) channels in T cells, whose function in mammalian physiology is not well understood. Mice expressing mutant Stim 1 had macrothrombocytopenia and an associated bleeding disorder. Basal intracellular $\mathrm{Ca}^{2+}$ levels were increased in platelets, which resulted in a preactivation state, a selective unresponsiveness to immunoreceptor tyrosine activation motif-coupled agonists, and increased platelet consumption. In contrast, basal $\mathrm{Ca}^{2+}$ levels, but not receptor-mediated responses, were affected in mutant $\mathrm{T}$ cells. These findings identify Stim 1 as a central regulator of platelet function and suggest a cell type-specific activation or composition of the CRAC complex.
\end{abstract}

\section{Introduction}

The regulation of intracellular $\mathrm{Ca}^{2+}\left(\left[\mathrm{Ca}^{2+}\right]_{\mathrm{i}}\right)$ is essentially involved in signaling processes in virtually all cells. In nonexcitable cells, including hematopoietic cells, $\mathrm{Ca}^{2+}$ is released from the ER via inositol 1,4,5-triphosphate-mediated ( $\mathrm{IP}_{3}$-mediated) receptor activation triggered by ligand-activated plasma membrane receptors. If the limited $\mathrm{Ca}^{2+}$ reservoir of the ER becomes exhausted, extracellular $\mathrm{Ca}^{2+}$ enters the cytoplasm by a mechanism known as store-operated $\mathrm{Ca}^{2+}$ entry (SOCE) $(1,2)$. Although electrophysiologically well defined for more than a decade, the molecular identity of the pivotal proteins undoubtedly involved in SOCE has been discovered only recently. Stromal interaction molecule 1 (Stim 1 ) is an ER resident protein necessary for the detection of ER $\mathrm{Ca}^{2+}$ depletion (3-6). The 4-transmembrane domain protein Orai1, or CRACM, was reported recently to confer SOC activity $(4,7-12)$. In T cells, Orai1 appears to be the predominant SOC (9), despite the fact that the C-terminal region of Stim 1 has been shown to also interact with other SOC candidates such as transient receptor potential channels (TRPCs) 1 ,

Nonstandard abbreviations used: $\left[\mathrm{Ca}^{2+}\right]_{i}$, intracellular $\mathrm{Ca}^{2+}$; $\mathrm{CRAC}, \mathrm{Ca}^{2+}$ releaseactivated; $\mathrm{IP}_{3}$, inositol 1,4,5-triphosphate; ITAM, immunoreceptor tyrosine activation motif; KLH, keyhole limpet hemocyanin; MK, megakaryocyte; MPV, mean platelet volume; PLC $\beta$, phospholipase C $\beta$; RC, rhodocytin; Sax, Saxcobuggotski (mouse); SERCA, sarcoplasmic/endoplasmic reticulum $\mathrm{Ca}^{2+}$ ATPase; SOCE, store-operated $\mathrm{Ca}^{2+}$ entry; Stim1, stromal interaction molecule 1; TG, thapsigargin; TPO, thrombopoietin.

Conflict of interest: J. Grosse, B. Schneider, L. Zeitlmann, P. Hanke, P. Schropp, C. Schmittwolf, W. Jagla, P. Yu, and M. Nehls received salary from Ingenium Pharmaceuticals AG and owned stock options or stocks in the past.

Citation for this article: J. Clin. Invest. 117:3540-3550 (2007). doi:10.1172/JCI32312.
2 , and 4 (13), and this interaction may be involved in SOCE in blood platelets (14).

Platelets, anucleated cells that originate from the cytoplasm of bone marrow megakaryocytes (MKs), circulate in the blood, surveying the integrity of the vascular system. At sites of vascular injury, they become activated and efficiently adhere to the exposed subendothelial matrix. The subsequent extension of the thrombus requires a rapid response of platelets to locally produced and released soluble agonists, including thrombin, $\mathrm{ADP}$, and $\mathrm{TXA}_{2}$, which amplify and sustain the initial cellular activation and recruit circulating platelets from the flowing blood, thereby promoting thrombus growth and stability $(15,16)$.

In platelets, 2 major signaling pathways mediate elevations in cytoplasmic $\mathrm{Ca}^{2+}$ concentrations and cellular activation. Soluble agonists such as thrombin, $\mathrm{ADP}$, and $\mathrm{TXA}_{2}$ stimulate receptors that couple to heterotrimeric $\mathrm{G}$ proteins $(\mathrm{G} \alpha \mathrm{q})$ and lead to activation of phospholipase $\mathrm{C} \beta$ (PLC $\beta$ ) (17). The other pathway is similar to that used by immunoreceptors and involves tyrosine phosphorylation cascades downstream of the receptor-associated immunoreceptor tyrosine activation motif(ITAM), culminating in the activation of PLC $\gamma 2$ (18). This pathway is triggered by activation of the collagen receptor GPVI (18) or CLEC-2 (19), the receptor for the snake venom toxin rhodocytin (RC). In both pathways, the activation of PLCs leads to the production of $\mathrm{IP}_{3}$ and diacylglycerol (DAG), but the subsequent molecular events contributing to SOCE and full cellular activation in platelets have remained elusive. Thus although SOCE is a universal process, the molecular machinery involved in distinct cell types is still poorly understood, as is the function of SOCE in mammalian physiology. 


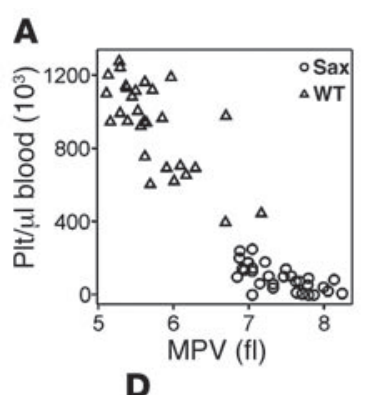

$\mathbf{B}$

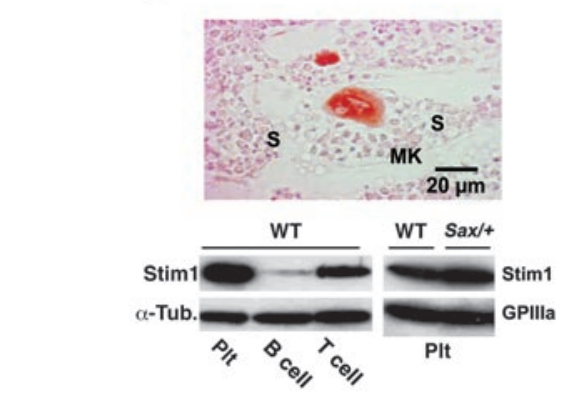

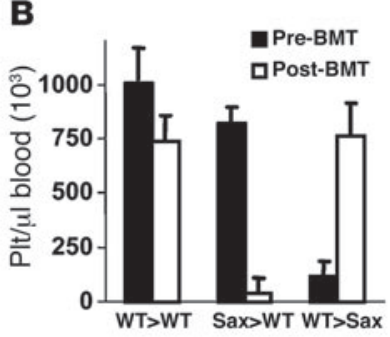

C

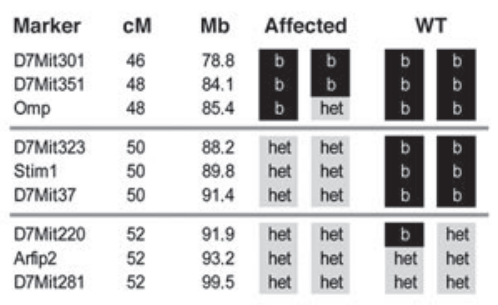

E $\quad$ E13.5
E13.5
E14.5

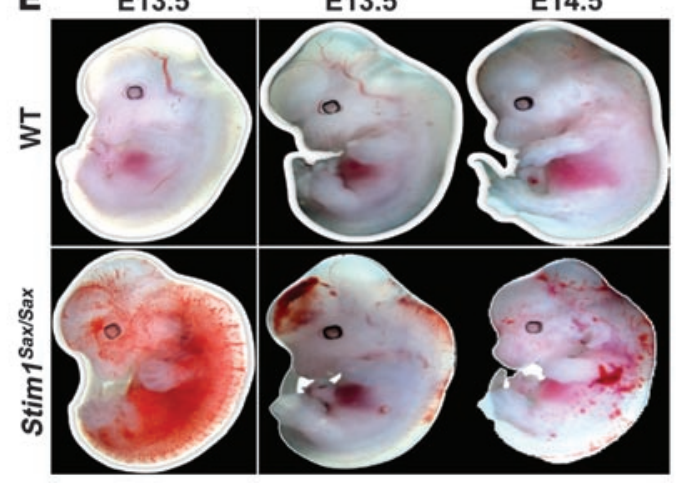

Figure 1

Isolated thrombocytopenia in Stim1Sax/+ mice. (A) Reduced platelet counts and increased MPV in Stim1 Sax/+ mice. (B) Platelet counts (PIt) before and after bone marrow transfer (BMT; $n \geq 7$ per group; ANOVA with post-hoc Scheffé; ${ }^{*} P<0.0001$. WT $\rightarrow$ WT (graft $\rightarrow$ host) and Stim1 1 Sax $/+\rightarrow$ WT were a homogenous subset before BMT; WT $\rightarrow$ WT and WT $\rightarrow$ Stim 1 Sax/+ were a homogenous subset after BMT. (C) Marker location and haplotypes of the animals defining the borders of the mapping region of the phenotypic trait. b, homozygous C57BL/6; het, heterozygous. (D) Top: Immunohistochemical staining of bone marrow reveals intense staining of MKs located adjacent to sinusoids (S). Bottom: Western blot analysis of Stim 1 expression in whole cell lysates (20 $\mathrm{gg} / \mathrm{lane}$ ) of WT platelets, T cells, and B cells. $\alpha$-Tubulin was used as a loading control. Comparison of Stim levels in WT and Stim 1 Sax/+ platelets. GPIIla is shown as a loading control. (E) Severe hemorrhage in different regions of the body of Stim1 ${ }^{\text {Sax/Sax }}$ embryos. Original magnification, x6.3.

We have generated a mouse line expressing an activating EF hand mutant of Stim 1 resulting in macrothrombocytopenia and an associated bleeding disorder. Basal $\left[\mathrm{Ca}^{2+}\right]_{i}$ levels are increased in platelets, resulting in a preactivation state, a selective unresponsiveness to ITAM-coupled agonists and increased platelet consumption. In contrast, immune cells are either not affected or are only mildly affected by the mutation, indicating that Stim 1 maybe of pivotal importance in the regulation of platelet function.

\section{Results}

A mouse line bearing a Stim1 mutation. We induced genome-wide random mutations using the chemical mutagen N-ethyl-N-nitrosourea. Offspring bred for homozygosity of the induced mutations were tested for abnormalities by visual inspection and a battery of neurological and behavioral tests and were also tested in parameters of hematology and clinical chemistry (20). A mouse line was established with dominant inheritance of elevated mean platelet volume (MPV) and reduced platelet counts in comparison with WT controls (Figure 1A). All other hematological parameters such as red and white blood cell counts and erythrocyte indices were not altered in 6-week- or 6-month-old mutant animals. The mouse line was named "Saxcoburggotski" (Sax). Both parameters, MPV and platelet counts, were later shown to reliably predict the genotype (100\% penetrance). Bone marrow transfer experiments showed that the platelet phenotype in the Sax line is transmitted with bone marrow $(\mathrm{Sax} \rightarrow \mathrm{WT})$ and can be completely rescued by WT bone marrow (WT $\rightarrow$ Sax) (Figure 1B).
Using animals outcrossed and backcrossed to C57BL/6, the phenotypic trait was mapped to chromosome 7 between the SNP marker Omp and microsatellite marker D7Mit220 (Figure 1C). Sequencing of genes located in the mapping region identified an A-to-G transition at nucleotide 444 in exon 2 of Stim1 (NM_ 009287), resulting in an amino acid exchange in the EF hand motif at position 84 (Asp84Gly, or D84G). The identified mutation, Stim $1^{\text {Sax }}$, was absent in the parental strains and cosegregated with the Sax phenotype in all animals tested.

Stim 1 has been shown to regulate $\mathrm{Ca}^{2+}$ release-activated (CRAC) channels in Jurkat T cells, but little is known about its expression in other cells of the hematopoietic system. In bone marrow we detected high levels of Stim 1 protein only in MKs of both WT and Stim $1^{\text {Sax/+ }}$ samples (Figure 1D and data not shown). In addition, western blot analysis revealed high levels of Stim 1 protein in platelets, whereas lower levels were detected in T cells (2.3-fold) and B cells (10.2-fold), suggesting that Stim 1 might play an important role in platelets (Figure 1D). No differences in Stim 1 expression levels were observed in these cells between WT and Stim $1^{\text {Sax } /+}$ mice.

To explore the phenotype of homozygous animals, heterozygous breeder pairs were set up. Only 1 homozygous animal was detected among 72 offspring, deviating from a Mendelian birth rate ( $\chi^{2}$ exact test, $P<0.001$ ), whereas the expected frequency was observed for heterozygotes (66\%) and WT (33\%) after exclusion of homozygotes. The hematological parameters of the homozygous animal were within the $95 \%$ percentile of the heterozygotes, sug- 
A

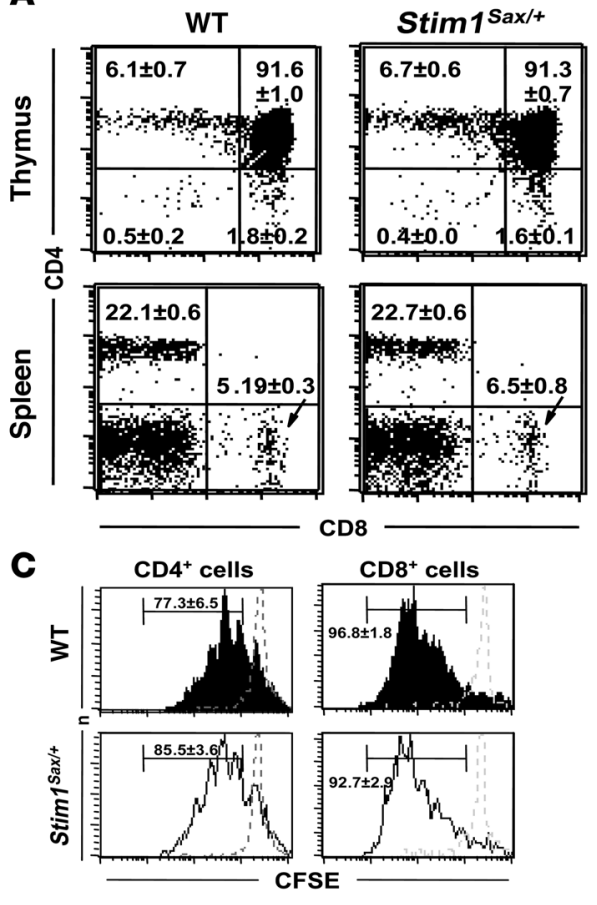

B
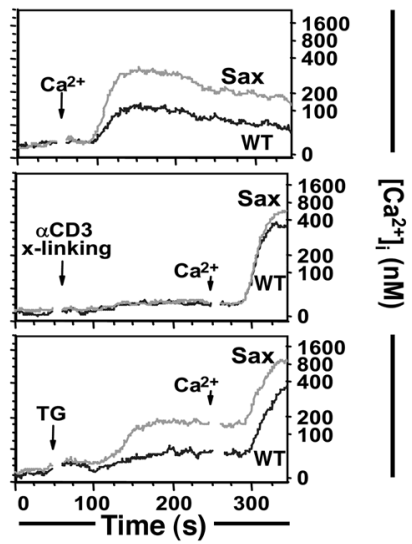

D

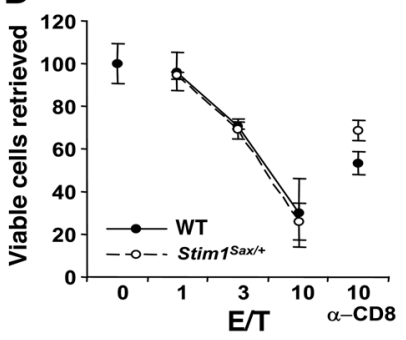

Figure 2

T cell function in Stim $1^{\text {Sax/+ }}$ mice. (A) Flow cytometric analysis of the CD4/CD8 distribution among thymocytes and splenocytes. Mean frequencies of cells per quadrant are given \pm SD ( $n=3$ per group). (B) Indo-1-labeled WT (black line) and Stim $1^{\text {Sax/+ }}$ (grey line) $\mathrm{CD} 4^{+} \mathrm{T}$ cells in $\mathrm{Ca}^{2+}$-free medium were left untreated (top), incubated with anti-CD3 antibodies followed by a crosslinking secondary antibody (middle), or stimulated with TG (bottom), and $\left[\mathrm{Ca}^{2+}\right]_{\mathrm{i}}$ levels were monitored. Addition of $0.4 \mathrm{mM}$ extracellular $\mathrm{Ca}^{2+}$ is indicated $\left(\mathrm{Ca}^{2+}\right.$ arrow). The data shown is representative of more than 6 individual experiments with virtually identical results. (C) CFSE-labeled splenocytes of the indicated genotype were either left unstimulated (dotted line) or stimulated with anti-CD3 mAb in solution (solid line) for 3 days prior to analysis of CFSE dye dilution among $\mathrm{CD}^{+}$and $\mathrm{CD}^{+}$cells. The numbers indicate the mean percentages of CFSE-low cells \pm SD ( $n=3$ per group). (D) $\mathrm{H}-2^{\mathrm{b}}$-primed lymph node cells of WT (closed circles) and Stim Sax/+ mice (open circles) were used as effector cells (E) against EL-4 target cells $(\mathrm{T})$. Blocking anti$\mathrm{CD} 8 \alpha$ antibody was added as indicated. gesting that Stim1 might play a critical role in embryonic development. Many residual bodies were detected at E7-E9, and only a few Stim $1^{\operatorname{Sax} / \operatorname{Sax}}$ embryos survived until E13-E14, although they displayed severe hemorrhages in different regions of the body (Figure 1E). At later stages, only material obtained from resorption sites, but not morphologically normal embryos, were genotyped as Stim $1^{\operatorname{Sax} / \text { Sax }}$. This indicates that Stim $1^{\operatorname{Sax} / \text { Sax }}$ mice suffer from additional, most likely vascular, defects that contribute to the observed embryonic lethality.

$T$ cell development and function in Stim $1^{\text {Sax/+ }}$ mice is essentially normal. Recently, Zhang et al. have demonstrated that the overexpression of EF hand mutants of Stim 1 constitutively activates CRAC channels in Jurkat $T$ cells in vitro (5), suggesting that Stim 1 might play a critical role in immunoreceptor signaling and $\mathrm{T}$ cell function (21). Therefore, the immune phenotype and $\mathrm{T}$ cell function was analyzed in Stim $1^{\text {Sax } /+}$ mice. Flow cytometric analysis of white blood cells from spleen, thymus, or lymph node from 4-week-old animals revealed no changes in numbers and distribution (data not shown). Similarly, the relative distribution of thymocyte subsets based on CD4 and CD8 expression and the prevalence of mature CD4 and CD8 T cells in the spleen were comparable (Figure 2A). Of note, we also did not observe any differences between Stim $1^{\text {Sax/+ }}$ and WT T cells with regard to the expression of activation markers or the frequency of cells with a memory phenotype or regulatory $\mathrm{CD} 4^{+} \mathrm{CD} 25^{+} \mathrm{T}$ cells (data not shown). However, in line with the proposed role of Stim 1 as a regulator of CRAC channels in T cells, CD $4^{+} \mathrm{T}$ cells of Stim $1^{\text {Sax } /+}$ mice showed spontaneous influx of extracellular $\mathrm{Ca}^{2+}$ and steady-state $\left[\mathrm{Ca}^{2+}\right]_{\mathrm{i}}$ was elevated approximately 2.8 -fold $( \pm 1.2, n=7$ experiments; $P=0.000845)$ compared with WT controls $(178 \pm 62 \mathrm{nM}$ versus $55 \pm 21 \mathrm{nM}, n=3$ per group; $P=0.0157$; Figure 2B). Despite this, anti-CD3 stimulation of WT and Stim $1^{\mathrm{Sax} /+} \mathrm{CD}^{+}$cells induced comparable release of $\mathrm{Ca}^{2+}$ from intracellular stores (slope, $0.36 \pm 0.09$ versus $0.27 \pm 0.20$, respectively; $n=3$ ). Subsequent $\mathrm{Ca}^{2+}$ influx was also similar between mutant and WT T cells (slope, $9.7 \pm 1.2$ versus $8.9 \pm 0.8$, respectively; $n=3$ ) (Figure $2 \mathrm{~B}$ ). To test SOCE in the mutant $\mathrm{T}$ cells, we stimulated them with the sarcoplasmic/endoplasmic reticulum $\mathrm{Ca}^{2+}$ ATPase (SERCA) pump inhibitor thapsigargin (TG), which evokes SOC influx. While the TG-evoked store release was increased approximately 2.5 -fold in the mutant cells (slope, $2.0 \pm 0.07$ compared with WT, $0.8 \pm 0.1 ; n=3$ ), the subsequent TG-dependent (store-operated) $\mathrm{Ca}^{2+}$ influx was comparable between WT and Stim $1^{\text {Sax } /+}$ cells (slope, $5.8 \pm 0.9$ versus $5.8 \pm 0.7$, respectively; $n=3$ ), suggesting largely functional SOCE in these cells (Figure 2B). In line with this, mutant $\mathrm{CD}^{+}$and $\mathrm{CD}^{+}$ $\mathrm{T}$ cells displayed an unaltered proliferative response to antiCD3 stimulation in whole splenocyte preparations as detected by flow cytometric analysis of CFSE dye dilution (Figure 2C). Furthermore, WT and Stim $1^{\text {Sax/+ }}$ cytotoxic T cells were equally potent, both in killing allogenic EL-4 cells in vitro (Figure 2D) and in mediating redirected lysis (data not shown). Similarly, all WT and mutant mice developed a keyhole limpet hemocyaninspecific (KLH-specific) $\mathrm{CD}^{+} \mathrm{T}$ cell response in vivo, as assayed by in vitro recall to KLH (data not shown), and equally high titers of anti-KLH immunoglobulins in the serum (WT, 1:104 and $1: 10^{5} ; \operatorname{Stim} 1^{\operatorname{Sax} /+}, 1: 10^{4}, 1: 10^{5}$, and $\left.1: 10^{5}\right)$. In contrast to $\mathrm{T}$ cells, no alterations of basal $\left[\mathrm{Ca}^{2+}\right]_{\mathrm{i}}$ were measured in Stim $1^{\mathrm{Sax} /+}$ granulocytes, monocytes, or B cells. The latter displayed normal proliferative responses to stimulation with anti-B cell receptor plus anti-CD40 in cultures of CFSE-labeled splenocytes (data not shown).

Splenomegaly and MK byperplasia. Despite the overall normal appearance of the immune cell compartment, Stim $1^{\text {Sax } /+}$ mice progressively develop bone marrow fibrosis, leading to a marked reduction of bone marrow cellularity and stromal degradation 
A

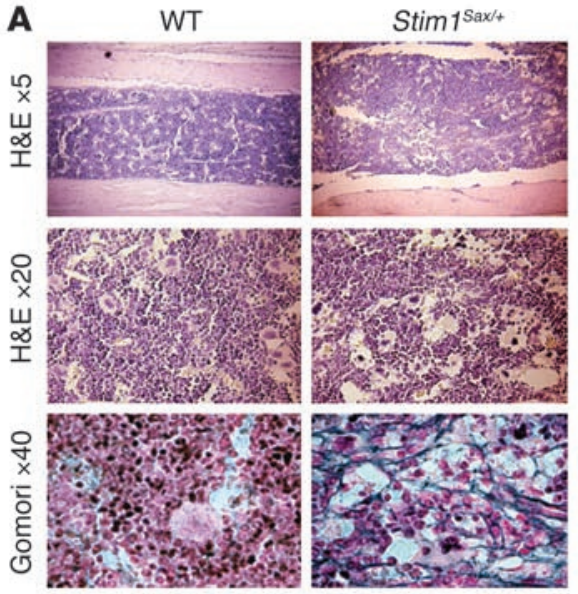

1 month

B

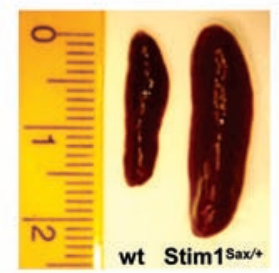

E

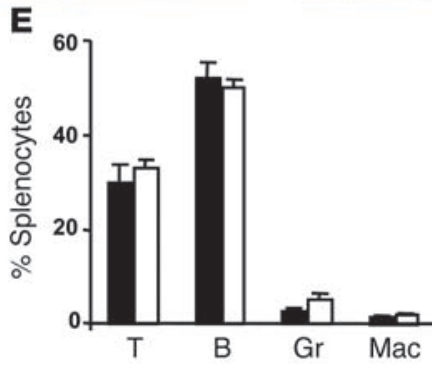

C

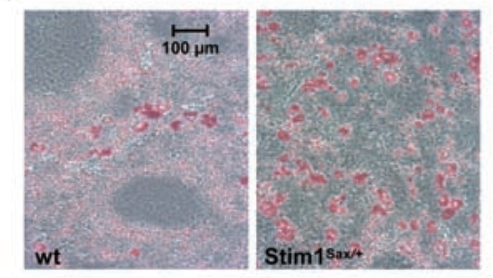

F
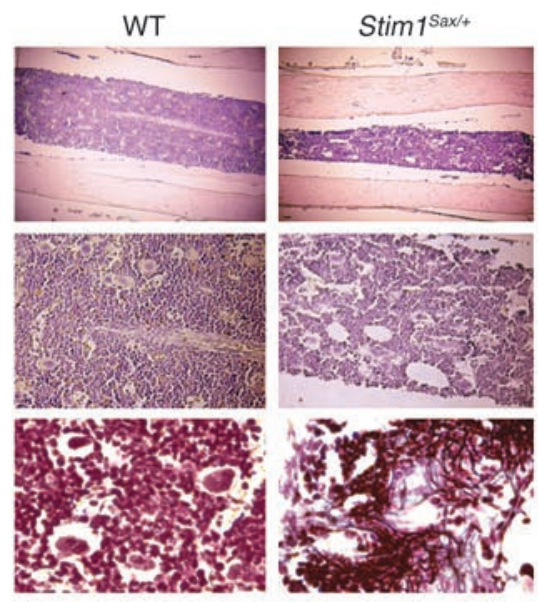

2 months

D

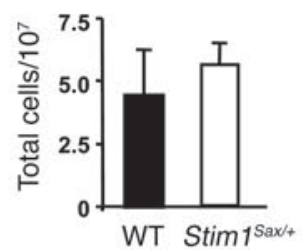

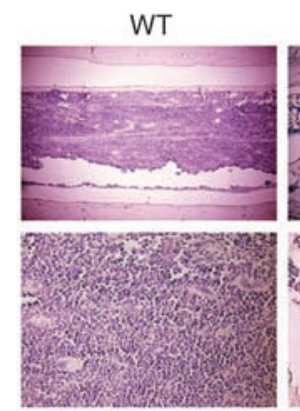
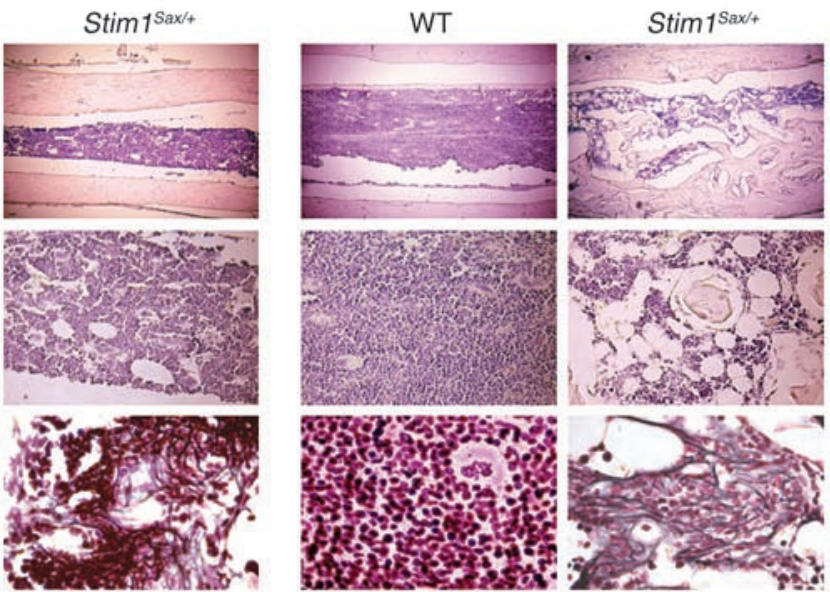

6 months

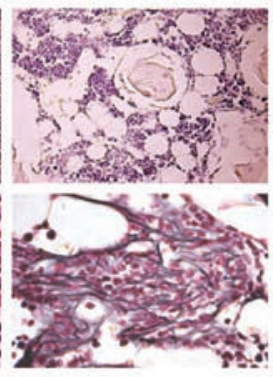

ํ:

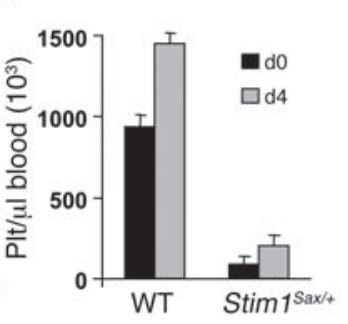

Figure 3

Bone marrow fibrosis, splenomegaly, and MK hyperplasia in Stim1Sax/+ mice. (A) Bone marrow fibrosis in Stim1Sax/+ mice. H\&E (top and middle rows) and Gomori stainings (bottom row) of femural bone marrow of WT and Stim $1^{\text {Sax } /+}$ mice at different ages. Note the increased collagen deposition and bone marrow destruction in the mutant animals. (B) Increased spleen size in 6-month-old Stim 1 Sax/+ mice. (C) Effacement of the $\mathrm{red} /$ white pulp architecture and increased numbers of mature MKs in spleens from 6-month-old Stim1Sax/+ mice. Cryosections were stained with anti-GPIb antibodies (red) and counterstained with hematoxylin. Total cell numbers (D) and leukocyte composition (E) in spleens from 6-monthold WT (black bars) and Stim 1 ${ }^{\text {Sax/+ }}$ (white bars) mice. (F) A 4-day TPO treatment caused a significant elevation of platelet counts in WT but not Stim 1 Sax/+ mice. d0, before treatment. $n=4$ per group; paired Student's $t$ test, $P<0.001$ ). Mean \pm SD.

affecting large parts of the femoral cavity at the age of 6 months (Figure 3A). In parallel, the animals developed a pronounced splenomegaly (Figure 3B) with a spleen/body mass ratio of $14.8 \% \pm 4.63 \%$ (WT, $4.1 \% \pm 0.23 \%$ ) at the age of 6 months. Histological analysis revealed complete effacement of normal splenic architecture, with marked expansion of the red pulp that was strongly enriched in mature MKs (mutant, $16.6 \pm 4.3$, versus WT, $4.4 \pm 1.3 \mathrm{MKs}$ per visual field), as shown by immunostaining for the late-stage MK differentiation markers GPIb (Figure 3C) and GPVI (data not shown). In contrast, at the age of 4 weeks (data not shown) and 6 months, the total cell counts in the spleen, as well as numbers of T and B cells, granulocytes, and monocytic cells were not increased (Figure 3, D and E).

To investigate the reason for the reduced platelet counts despite elevated MK numbers, we measured serum thrombopoietin (TPO) levels, which are regulated by total platelet mass and are known to trigger MK induction, proliferation, and differentiation. TPO levels of Stim $1^{\text {Sax/+}}$ animals were not different from WT controls (data not shown). Injection of TPO induced significant elevations in the platelet counts of WT animals $\left(514 \times 10^{3} \pm 72 \times 10^{3} / \mu \mathrm{l}\right)$, but only nonsignificant elevations in Stim $1^{\text {Sax } /+}$ animals $\left(114 \times 10^{3} \pm 89 \times 10^{3} / \mu \mathrm{l}\right)$, despite starting from much lower values, thus excluding insufficient TPO levels as a cause of the thrombocytopenia (Figure 3F).

Another possible cause for the observed thrombocytopenia is a cell-autonomous reduction in platelet biogenesis as described for mice with ablated transcription factors GATA1 or NF-E2 $(22,23)$. In Stim $1^{\text {Sax } /+}$ animals, polyploid mature MKs with lobulated nuclei and normal ultrastructure were found in their appropriate location in close contact with bone marrow sinusoids, suggesting no obvious defect in MK differentiation (Figure 4, A and B). This notion was further supported by the analysis of proplatelet forma- 

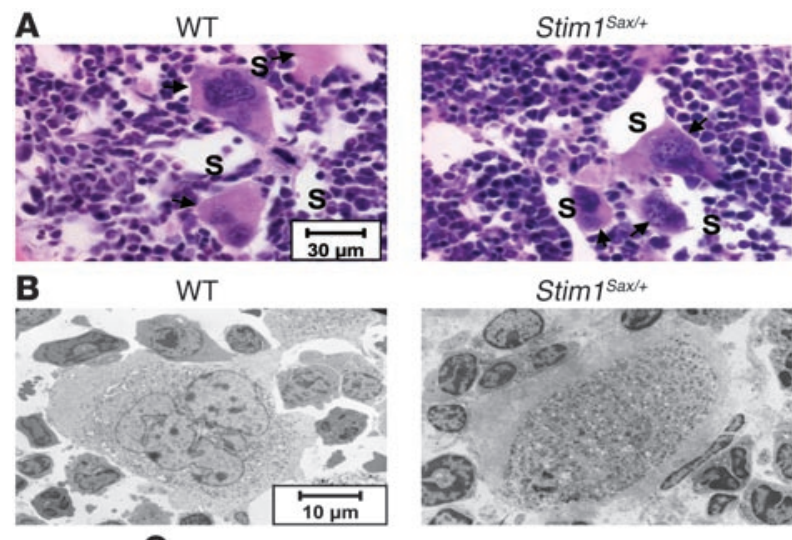

C

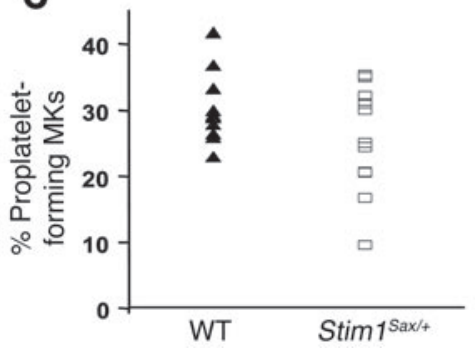

tion in fetal liver-derived MK cultures. There was no significant difference in either the number of MK-generating proplatelets $(P>0.05)$ (Figure 4C) or in the complexity of the formed proplatelets (data not shown).

Platelet preactivation and reduced life span. Besides impaired thrombopoiesis, increased clearance of platelets is a possible explanation for the thrombocytopenia. To test this hypothesis, we administered a nonsaturating dose of an Alexa Fluor 488-labeled noncytotoxic antibody against the platelet-specific GPIb-IX complex, and the percentage of fluorescence-tagged platelets in the circulation was monitored for 5 days by flow cytometry. In conjunction with published platelet life times, we detected a decline of the fluorescent population in WT animals over 5 days (24) (Figure 5A). In sharp contrast, in Stim $1^{\text {Sax/+ }}$ mice the labeled platelet population was reduced to approximately $27 \%$ after 24 hours and even further, to approximately $4 \%$ and $0 \%$ on days 2 and 3 , respectively, demonstrating a markedly reduced platelet life span. A similar result was also obtained when the experiment was carried out in lethally irradiated WT mice that had been transplanted with WT or Stim1Sax/+ bone marrow 4 weeks before the experiment (Figure 5A), excluding an involvement of cells of nonhematopoietic origin in the increased clearing of the cells. Since the spleen is the major organ for clearance of aged platelets, mice were splenectomized and platelet counts were followed. This treatment yielded a significant increase in platelet numbers in WT controls, whereas only a very minor and transient effect was observed in Stim $1^{\text {Sax } /+}$ mice (Figure 5B), suggesting that premature aging is not the cause for the decreased platelet life span. In agreement with this, the surface levels of GPIb $\alpha$, which has been shown to become proteolytically cleaved in aging platelets (25), were not reduced but rather slightly increased in the mutant cells, as were other prominent surface glycoproteins, including GPV, integrin $\alpha \mathrm{IIb} \beta 3$, and CD9 (Table 1).

An alternative explanation for the decreased platelet life span could be a preactivation state of the cells leading to their increased intravascular consumption. Basic platelet $\left[\mathrm{Ca}^{2+}\right]_{\mathrm{i}}$ was approxi-

\section{Figure 4}

Normal MK differentiation and morphology in Stim 1 Sax/+ mice. (A) Large polyploid MKs (arrows) are observed in close contact with the sinusoidal endothelium. The morphology of WT and Stim1Sax/+ MKs does not differ. (B) No systematic differences were observed in ultrastructural investigation of MKs. The perinuclear, intermediate, and ectoplasmic compartment can be clearly distinguished. (C) Only slightly reduced proplatelet formation of fetal liver-derived MK cultures from Stim 1 Sax/+ mice were found as compared with the WT control. The results shown are representative of 3 individual experiments.

mately 3 -fold increased in Stim $1^{\text {Sax/+ }}$ platelets as compared with WT (Stim $1^{\text {Sax } /+}, 54.3 \pm 15.2 \mathrm{nM}[n=14]$ versus WT, $18.3 \pm 7.2 \mathrm{nM}[n=6]$; $P<0.001$ ) (Figure 5C), suggesting the presence of constitutively activated SOC channels in those cells. This was further confirmed when the cells were exposed to alternating extracellular $\mathrm{Ca}^{2+}$ concentrations. In the absence of extracellular $\mathrm{Ca}^{2+}$, the mutant cells showed similar $\left[\mathrm{Ca}^{2+}\right]_{\mathrm{i}}$ to that of the WT controls $(27.7 \pm 8.2$ versus $17.3 \pm 7.6 \mathrm{nM}$, respectively; $n=3$ per group). Addition of $2 \mathrm{mM} \mathrm{Ca}^{2+}$ had virtually no effect on WT platelets but led to an increase of $\left[\mathrm{Ca}^{2+}\right]_{\mathrm{i}}$ up to $78.9 \pm 14.3 \mathrm{nM}$ in the mutant cells. This was reversed upon removal of extracellular $\mathrm{Ca}^{2+}$ and reestablished when $\mathrm{Ca}^{2+}$ was added again (Figure 5D).

Increased $\left[\mathrm{Ca}^{2+}\right]_{i}$ is normally only found upon agonist-induced platelet activation, characterized by cytoskeletal rearrangement and a change from discoid to spherical shape, activation of integrins, release of intracellular granules, and finally, surface exposure of phosphatidyl serine-mediating procoagulant activity of the cells. Therefore, these activation parameters were analyzed in resting and activated Stim $1^{\text {Sax } /+}$ platelets. Electron microscopy revealed that platelet organelles were less strictly organized, with irregular distribution of the canalicular membrane system, and platelet shape was not as flat as in WT platelets. The marginal microtubular bundles located at the cellular equator in WT platelets were markedly reduced in Stim $1^{\operatorname{Sax} /+}$ platelets (Figure 5E). As reorganization of microtubules is an early event during platelet activation, this indicates that Stim $1^{\text {Sax/+ }}$ platelets might indeed be in a preactivated state. This was confirmed by flow cytometric detection of low but consistent levels of activated integrin $\alpha \operatorname{IIb} \beta 3$ in the unstimulated cells using the JON/A-PE antibody (26) (Figure 5F). In contrast, neither surface expression of P-selectin (a marker for $\alpha$ granule release) nor phosphatidyl serine exposure (as determined by Annexin A5-FITC binding) was detectable in those cells (data not shown). The preactivation state of Stim $1^{\text {Sax } /+}$ platelets was further confirmed by stimulating them with the $\mathrm{G}_{\mathrm{z}}$-activating agonist epinephrine $(10 \mu \mathrm{M})$, which alone is unable to induce activation of WT platelets but enhances responses to agonists that mobilize $\left[\mathrm{Ca}^{2+}\right]_{\mathrm{i}}(27)$. While WT platelets failed to respond to this stimulus, a robust increase in integrin $\alpha \operatorname{IIb} \beta 3$ activation was detected in the mutant cells (Figure 5F).

Defective collagen responses and thrombus formation. The above results suggested the presence of constitutively activated SOC channels in Stim $1^{\text {Sax/+ }}$ platelets. To test the consequences of this defect on SOCE, the cells were stimulated with TG. TG-evoked store release occurred significantly faster in the mutant cells but was reduced by approximately $60 \%$ as compared with the WT control. Similarly, the subsequent TG-dependent $\mathrm{Ca}^{2+}$ influx was reduced by approximately $70 \%$ in Stim $1^{\mathrm{Sax} /+}$ cells as compared with WT, demonstrating largely defective SOC activation (Figure 6, A and B). Next we tested the consequences of increased basal $\left[\mathrm{Ca}^{2+}\right]_{\mathrm{i}}$ and defective SOCE 
A

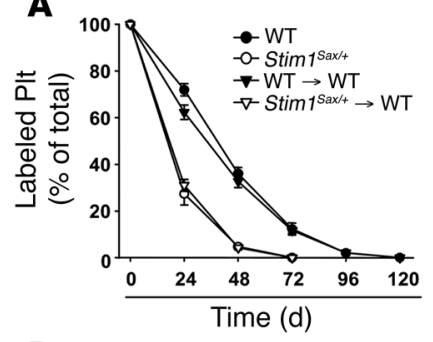

D

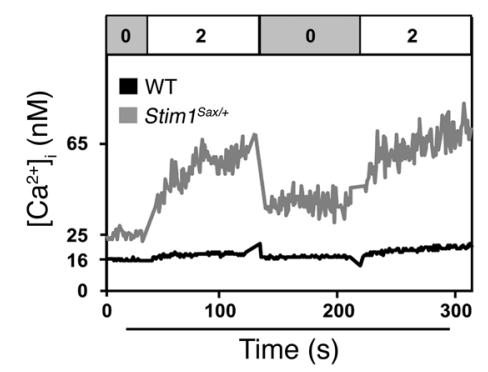

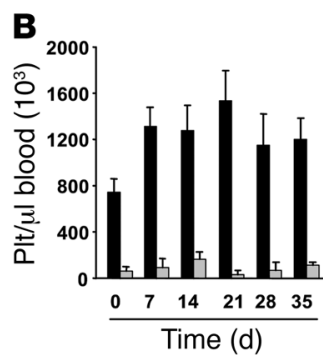

$\mathbf{E}$

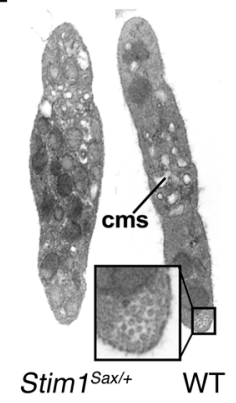

Figure 5

Preactivation and decreased life span of Stim $1^{\text {Sax/++ }}$ platelets. (A) The circulating platelet population was fluorescently labeled in the indicated mice and the portion of labeled cells in the total platelet population was monitored by flow cytometry ( $n=6$ per group). The total platelet count did not change significantly during the experiment. (B) Platelet counts in WT (black bars) and Stim 1 Sax/+ (gray bars) mice prior to (d0) and at the indicated time points after splenectomy. (C) Basal $\mathrm{Ca}^{2+}$ concentrations in WT and Stim $1^{\text {Sax } /+}$ platelets were measured in the presence or absence of 2 mM extracellular $\mathrm{Ca}^{2+}$. (D) Oregon Green BAPTA-1/FuraRed-loaded WT and Stim1 1 Sax/+ platelets were exposed to alternating extracellular $\mathrm{Ca}^{2+}$ concentrations, and $\left[\mathrm{Ca}^{2+}\right]_{\mathrm{i}}$ concentrations were monitored by flow cytometry $(\mathrm{E})$ Transmission electron microscopy reveals the absence of the marginal band of microtubules (inset) and a less prominent canalicular membrane system (cms) in Stim1 $1^{\text {Sax/+ }}$ platelets. Original magnification, $\times 9,500$; inset, $\times 27,000$. (F) Increased basal levels of activated integrin $\alpha$ llb $\beta 3$ (JON/A-PE) were detectable in unstimulated and epinephrinestimulated Stim 1 Sax/+ platelets. A PE-conjugated isotype control antibody yielded identical negative signals in WT and mutant platelets (data not shown). The results are expressed as mean fluorescence intensity \pm SD of 9 experiments.

for agonists evoking $\mathrm{Ca}^{2+}$ entry via $\mathrm{G}$ protein-coupled (thrombin, ADP, $\mathrm{TXA}_{2}$ ) or ITAM-coupled (collagen related peptide [CRP], RC) receptors. Stimulation of WT platelets with thrombin $(0.1 \mathrm{U} / \mathrm{ml})$ or a combination of ADP $(10 \mu \mathrm{M})$ and $\mathrm{U} 46619(1 \mu \mathrm{M})$ yielded similar increases in $\left[\mathrm{Ca}^{2+}\right]_{\mathrm{i}}$ in WT and mutant platelets (Figure 6, $\mathrm{C}$ and D). In marked contrast, stimulation with the GPVI-specific agonist CRP or the CLEC-2 agonist RC yielded profound rises in $\left[\mathrm{Ca}^{2+}\right]_{\mathrm{i}}$ in WT platelets but only minor responses in Stim $1^{\mathrm{Sax} /+}$ platelets (Figure 6, C and D). These results suggested that Stim $1^{\operatorname{Sax} /+}$ specifically interferes with ITAM- but not Gq-dependent platelet activation. This was confirmed by flow cytometric analysis of integrin $\alpha \mathrm{IIb} \beta 3$ activation and P-selectin exposure in response to different agonists. The G protein-coupled agonists thrombin and ADP (Figure 6E) as well as the combination of ADP and the stable $\mathrm{TXA}_{2}$ analog U46619 (data not shown) induced comparable responses in WT and Stim $1^{\operatorname{Sax} /+}$ platelets. In contrast, the ITAM-coupled agonists CRP and RC induced strong and irreversible activation of WT platelets but virtually no response in the mutant cells (Figure 6, C and D). This defect was not a consequence of the elevated basal $\left[\mathrm{Ca}^{2+}\right]_{\mathrm{i}}$ in Stim $1^{\mathrm{Sax} /+}$ cells, as an increase in $\left[\mathrm{Ca}^{2+}\right]_{\text {, }}$, induced for up to 30 minutes in WT platelets by the Gq-PLC $\beta$-stimulating agonist serotonin $(10 \mu \mathrm{M})$, did not reduce subsequent CRP- or RC-induced activation of the cells (data not shown).

C

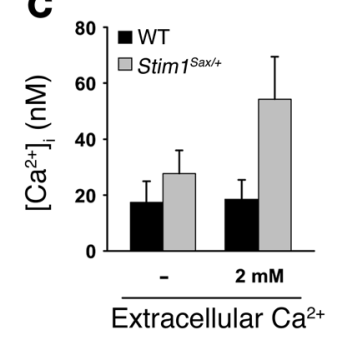

$\mathbf{F}$

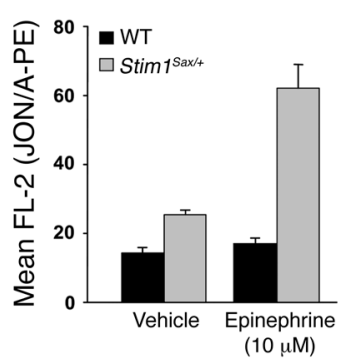

GPVI is the major platelet collagen receptor and essential for platelet activation and thrombus growth on the matrix protein (28). Therefore, the interaction of Stim $1^{\text {Sax/+ }}$ platelets with fibrous collagen was tested in a whole-blood perfusion assay (28). Control platelets at appropriately reduced counts readily established firm adhesions on the collagen fibers and rapidly built stable 3 dimensional aggregates. In contrast, the vast majority of Stim $1^{\operatorname{sax} /+}$ platelets that initially came in contact with the collagen either detached within a few seconds or translocated along the fibers before stable adhesion was established. Threedimensional thrombi were not formed in these samples. As a result, the surface area covered by platelets at the end of the experiment was markedly reduced in the mutant mice (Figure 7A). Thus $\operatorname{Stim} 1^{\operatorname{Sax} /+}$ mice showed reduced platelet counts and a selective impairment of the cells to interact with collagen, which is considered the most thrombogenic constituent of the vessel wall and a major trigger of thrombus formation at sites of vascular injury (16). To test the impact of this combined defect on hemostasis, tail bleeding times were determined and found to be significantly prolonged in $\operatorname{Stim} 1^{\mathrm{Sax} /+}$ mice (Figure 7B). In parallel analyses, blood loss was found to be significantly larger in the Stim $1^{\mathrm{Sax} /+}$ group (total blood loss, $59 \mu \mathrm{l}$; $95 \%$ confidence interval, 43-75 $\mu \mathrm{l})$ than in WT littermates $(11 \mu \mathrm{l} ; 95 \%$ confidence interval, 2-19 $\mu \mathrm{l})$. This severe hemostatic defect also translated into defective pathological thrombus formation as assessed in a model of arterial thrombosis, in which the abdominal aorta is mechanically injured and blood flow is monitored by an ultrasonic flow probe. In this model, thrombus formation is triggered predominantly by collagen and thus occurs in a GPVI/ITAM-dependent manner (29). While all WT animals formed irreversible occlusions within 15 minutes, no occlusive thrombus formation occurred in the $\operatorname{Stim} 1^{\mathrm{Sax} /+}$ group for up to 30 minutes (Figure 7C). Next, the mice were tested in a model of ferric chloride-induced injury of mesenteric arterioles, where thrombus formation is largely driven by thrombin and is less dependent on GPVI/ITAM signaling (30). Despite their reduced platelet count, 67\% (12/18) of the Stim 1 Sax $/+$ mice formed occlusive thrombi in this model within the same time frame as WT controls (11/12 vessels occluded) (Figure 7, $\mathrm{D}$ and $\mathrm{E})$. These results demonstrate that the Sax mutation yields selective protection from collagen-dependent thrombosis but also increases bleeding times in mice.

\section{Discussion}

Targeted mutations of the acidic residues coordinating $\mathrm{Ca}^{2+}$ binding to the EF hand motif of Stim 1 have been used to demonstrate its capacity to activate CRAC channels in Jurkat T cells $(4,5)$. 
Table 1

Platelet membrane glycoprotein expression in Stim 1 Sax $/+$ platelets

$\begin{array}{lcc} & \text { WT } & \text { Stim }^{\text {Sax } /+} \\ \text { GPIb } & 719 \pm 65 & 909 \pm 52 \\ \text { GPV } & 283 \pm 65 & 329 \pm 19 \\ \text { GPIX } & 440 \pm 54 & 553 \pm 33 \\ \text { GPVI } & 56 \pm 3 & 52 \pm 4 \\ \alpha 2 & 53 \pm 4 & 54 \pm 4 \\ \alpha 5 & 35 \pm 2 & 36 \pm 4 \\ \alpha \text { llb } \beta 3 & 728 \pm 21 & 882 \pm 30 \\ \text { CD9 } & 1,569 \pm 95 & 1,541 \pm 146\end{array}$

Diluted whole blood was stained with fluorophore-labeled antibodies at saturating concentrations for 15 minutes at room temperature and analyzed directly on a FACSCalibur. Platelets were gated by forward scatter/side scatter characteristics and FL4 positivity (PE/Cy5-conjugated anti-GPIb $\alpha$ or anti- $\alpha$ llb $\beta 3$ ). Results are given as the mean fluorescence intensity \pm SD of $6-12$ mice per group.

In line with this model, we found increased basal $\mathrm{Ca}^{2+}$ levels in the presence but not absence of extracellular $\mathrm{Ca}^{2+}$ in $\operatorname{Stim} 1^{\mathrm{Sax} /+} \mathrm{T}$ lymphocytes (Figure 2B), suggesting constitutive activation of CRAC channels in those cells. Unexpectedly, however, this did not lead to major alterations in $\mathrm{T}$ cell development in vivo or the cells' capacity to respond to stimuli. Despite the presence of other $\mathrm{Ca}^{2+}$ channels (31), CRAC channels are the most important route of $\mathrm{Ca}^{2+}$ entry into $\mathrm{T}$ cells (32). The long-standing question of the molecular identity of the CRAC channel was recently resolved with the discovery of ORAI1, highlighting the importance of this pathway, as ORAI1 mutations result in immunodeficiency due to the lack of SOCE in T lymphocytes (9). The incomplete activation of this pathway in Stim $1^{\mathrm{Sax} /+}$ mice might be due to the constitutive activation of only part of the available proteins, leaving the remainder functional for proper activation by store depletion. Moreover, the cells might partially compensate for the chronic ORAI1 activation by evoking inhibitory mechanisms. STIM2, closely related to STIM1, has been shown to be a strong inhibitor of SOCE when coexpressed with a STIM1 variant rendered constitutively active by an EF hand mutation (33). Another negative regulator of SOCE is an alternative splice variant of the myelin basic protein termed "Golli." T lymphocytes of Golli-deficient mice are hyperproliferative and show enhanced SOCE after T cell receptor stimulation (34).

Elevated $\left[\mathrm{Ca}^{2+}\right]_{\mathrm{i}}$ is mandatory to induce a proliferation of $\mathrm{T}$ lymphocytes, but instead of a constantly elevated SOCE, an oscillatory $\mathrm{Ca}^{2+}$ signal maintained over several hours is necessary. This is mediated by the complex interplay of several internal and plasma membrane $\mathrm{Ca}^{2+}$ channels and transporters as well as $\mathrm{Ca}^{2+}$ buffering organelles (32). Despite the elevated basal $\left[\mathrm{Ca}^{2+}\right]_{\mathrm{i}}$, the proliferation in response to $\mathrm{T}$ cell receptor activation is not disturbed in Stim $1^{\text {Sax } /+}$ mice, suggesting that functionally important spatial and temporal features of the $\left[\mathrm{Ca}^{2+}\right]_{\text {i }}$ pattern are maintained.

\section{Figure 6}

A selective ITAM signaling defect in Stim 1 Sax/+ platelets. (A and B) Oregon Green BAPTA-1/ FuraRed-loaded platelets were stimulated with $5 \mu \mathrm{M}$ TG for 10 minutes followed by addition of extracellular $\mathrm{Ca}^{2+}$, and $\left[\mathrm{Ca}^{2+}\right]_{i}$ was monitored by flow cytometry. Representative measurements $(\mathbf{A})$ and maximal $\left[\mathrm{Ca}^{2+}\right]_{i} \pm \mathrm{SD}$ ( $n=6$ per group) before and after addition of $2 \mathrm{mM} \mathrm{Ca}^{2+}(\mathbf{B})$ are shown. (C and $\left.\mathbf{D}\right)$ Oregon Green BAPTA-1/FuraRed-loaded platelets were stimulated with the indicated agonists in the presence of $2 \mathrm{mM} \mathrm{Ca}^{2+}$, and $\left[\mathrm{Ca}^{2+}\right]_{\mathrm{i}}$ was monitored by flow cytometry. Representative measurements $(\mathbf{C})$ and maximal $\left[\mathrm{Ca}^{2+}\right]_{\mathrm{i}}$ $\pm \mathrm{SD}$ ( $n=6$ per group) (D) are shown. (E) WT and Stim 1 Sax/+ platelets were stimulated with the indicated agonists, incubated with fluorophore-labeled antibodies to detect integrin $\alpha$ llb33 activation (JON/A-PE) and degranulation (anti-P-selectin FITC), and analyzed directly. Platelets were gated by forwardscatter/side-scatter characteristics and FL4 positivity (anti-GPIb-Cy5). The results shown are representative of 12 experiments.
A

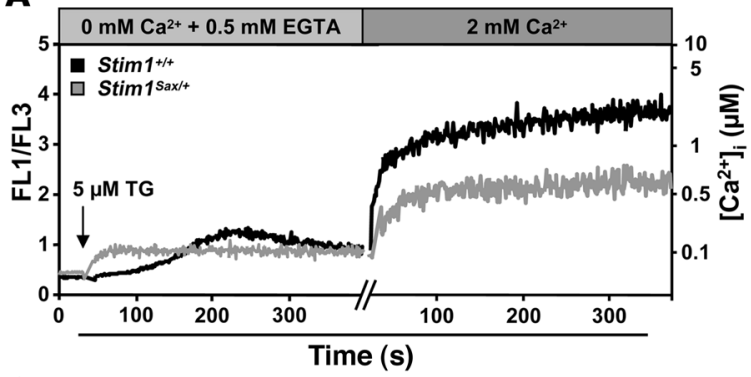

C

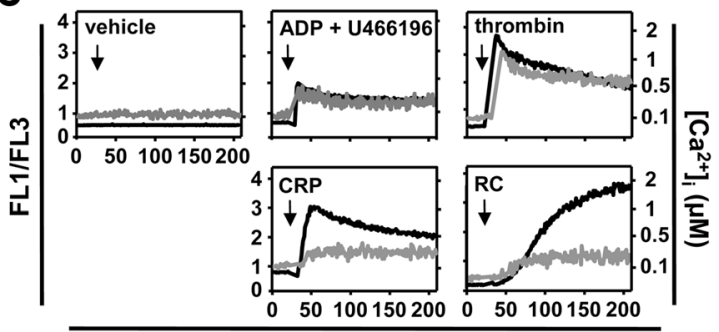

Time (s)

E
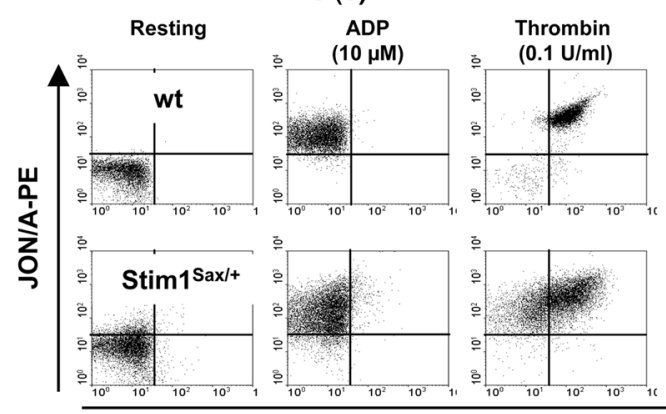

B

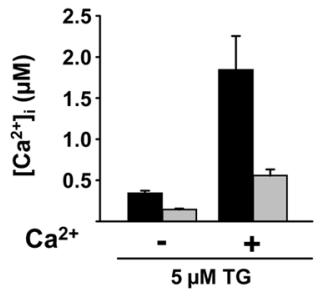

D

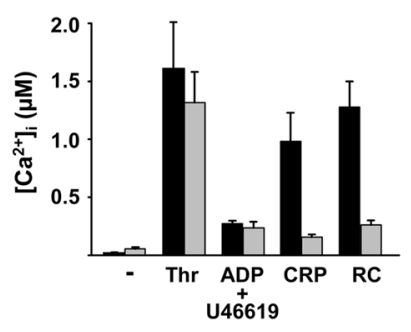

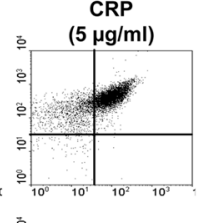

RC
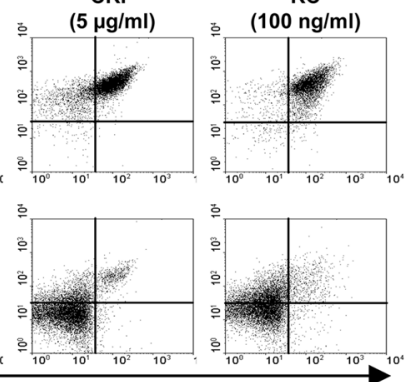

Anti-P-selectin FITC 

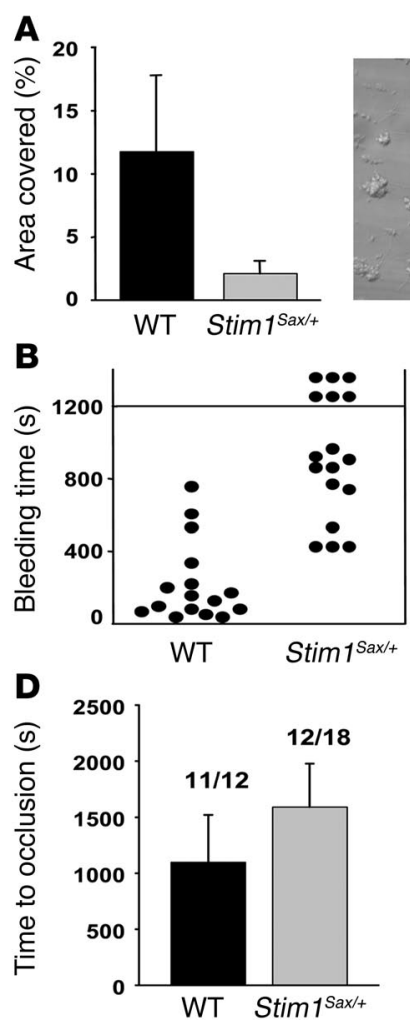

E
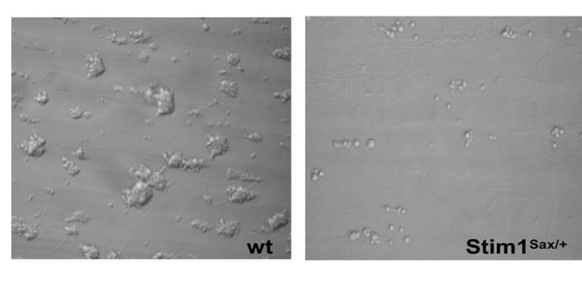

C
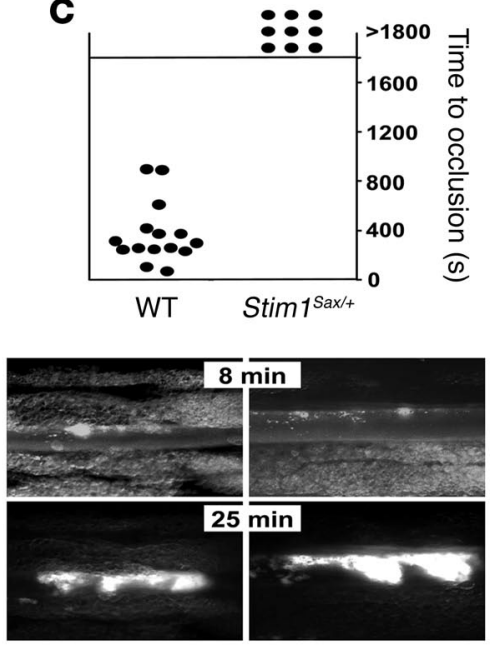

\section{Figure 7}

Defective collagen responses, bleeding, and selective resistance to collagen-dependent thrombosis in Stim 1 Sax/+ mice. (A) WT blood with appropriately reduced platelet counts and Stim 1 Sax/+ blood was perfused over a collagen-coated surface at a wall shear rate of $1,000 / \mathrm{s}$ for 4 minutes. Left: Surface area covered by platelets/thrombi is given as mean of 6 experiments \pm SD. Right: representative phase contrast images taken at the end of the experiment. (B) Tail bleeding times were monitored for 15 minutes. (C) The abdominal aorta was mechanically injured and blood flow was monitored for 40 minutes or until complete occlusion occurred. (B and $\mathbf{C}$ ) Each symbol represents one individual. (D and $\mathbf{E}$ ) Thrombosis was induced in mesenteric arterioles by topical application of $\mathrm{FeCl}_{3}$ and the time to complete occlusion was determined by intravital microscopy. (E) Representative pictures of one experiment where occlusion occurred in both the WT and Stim $1 \mathrm{Sax} /+$ mouse. Indicated time points represent minutes after $\mathrm{FeCl}_{3}$-induced injury. Original magnification, $\times 400(A), \times 100(E)$.
In analogy to $\mathrm{T}$ cell receptor stimulation, activation of the ITAM-associated GPVI collagen receptor and CLEC-2 in platelets results in $\mathrm{Ca}^{2+}$ release from internal stores via a phosphorylation cascade involving PLC $\gamma 2$ activation. Similar to T cells, basal $\left[\mathrm{Ca}^{2+}\right]_{\mathrm{i}}$ is elevated by a factor of 3 in Stim $1^{\mathrm{Sax} /+}$ platelets. In contrast to $\mathrm{T}$ cells, however, the platelets are in a preactivated state, with abrogation of ITAM receptor-mediated activation and a reduced survival time. The reason for this difference is not clear, but it is likely based on different counterregulating mechanisms operating in these cell types. Inhibitors of Stim1-dependent SOCE, such as Stim2 (33) or other, yet unknown proteins, might be differently expressed, display altered activity, or interact with different binding partners under conditions of constitutive SOC channel activation and thereby inhibit unlimited $\mathrm{Ca}^{2+}$ influx and/or subsequent cellular activation that would ultimately lead to cell death. Based on these assumptions, one may speculate that in $\mathrm{T}$ cells these compensatory mechanisms are better adjusted than in platelets, possibly because de novo protein synthesis is very limited in the latter due to the absence of a nucleus. Further studies will be required to address this question. Furthermore, SOCE in $\mathrm{T}$ lymphocytes needs to be maintained for hours or even days, whereas full and irreversible activation of platelets occurs within a few seconds. These differences might require a finely tuned balance of all players involved in T lymphocyte SOCE, whereas platelets are optimized for fast responses.

In resting cells a constant $\mathrm{Ca}^{2+}$ leak from the ER is opposed by the activity of SERCA pumping the $\mathrm{Ca}^{2+}$ back into the ER. This passive leak current has been shown to be mediated mainly by presenilins (35). The earlier onset and different peak values of the TG-induced $\left[\mathrm{Ca}^{2+}\right]_{\mathrm{i}}$ elevation in Stim $1^{\mathrm{Sax} /+}$ platelets suggests that the $\mathrm{Ca}^{2+}$ leak could be constitutively larger as a consequence of ele- vated $\mathrm{ER} \mathrm{Ca}^{2+}$ concentrations. In addition, the activity of SERCA might be elevated, resulting in a different response to TG.

In addition to ITAM receptor activation, a positive feed back response to secreted platelet products such as ADP and $\mathrm{TXA}_{2}$ as well as locally generated thrombin is required for the formation of a stable thrombus. These ligands activate Gq-coupled GPCRs, which results in activation of PLC $\beta$ and $\mathrm{IP}_{3}$-mediated $\mathrm{Ca}^{2+}$ release. In addition, the other branch of the signaling cascade seems to be important in the case of PLC $\beta$ activation, as DAG and some of its metabolites have been shown to induce non-SOCE (36). The existence of non-SOCE has been demonstrated in platelets, and members of the TrpC family have been suggested as candidates mediating both SOCE and non-SOCE $(2,14,37)$. Furthermore, $\mathrm{IP}_{3}$ receptors have been shown to mediate non-SOCE in B lymphocytes (38). Interestingly, the $\mathrm{IP}_{3}$ receptor has been detected in the platelet plasma membrane (39). Thus the elevation of $\left[\mathrm{Ca}^{2+}\right]_{i}$ elicited by GPCRs might be mediated predominantly via nonSOCE or be due to release from internal stores without much involvement of $\mathrm{Ca}^{2+}$ entry. SOCE and at least some of the nonSOCE pathways are mutually exclusive and could be employed alternatively depending on the filling state of the cellular stores $(36,40)$. This implies the possibility that the Stim $1^{\text {Sax }}$ mutation alters the ratio between these $2 \mathrm{Ca}^{2+}$ entry pathways.

The alteration of platelet function is the predominant phenotype in the Stim $1^{\text {Sax/+ }}$ mouse. This suggests that mutations of human STIM1 and other proteins involved in SOCE are candidate genes for inherited thrombocytopenias. Wiskott-Aldrich syndrome (WAS) and X-linked thrombocytopenia are caused by a variety of frame shift, missense, and nonsense mutations in the WAS gene. The WAS protein is involved in reorganization of the actin cytoskeleton, which might be important for the proper 
localization of the specialized ER domains and other components involved in SOCE (4). Both syndromes are characterized by a combination of thrombocytopenia, small platelets, and a progressive decrease in $\mathrm{T}$ lymphocyte number and function, leading ultimately to immunodeficiency in WAS patients (41). This constellation suggests that alteration of SOCE might be involved in the pathophysiology of these and other syndromes, most notably idiopathic myelofibrosis, which resembles many of the alterations found in Stim $1^{\text {Sax/+ }}$ mice (42).

\section{Methods}

Mice, mutagenesis, positional cloning, and genotyping. $\mathrm{C} 3 \mathrm{HeB} / \mathrm{FeJ}$ (catalog no. 000658), C57BL/6J (catalog no. 000664), C57BL/6J Ly5.1 (CD45.1) (catalog no. 002014) mice were obtained from the Jackson Laboratory and kept at a 12-hour light/12-hour dark cycle with food and water available ad libitum in full barrier specific pathogen-free facilities according to the Federation of European Laboratory Animal Science Associations (43). Mouse breeding and all experimental procedures were approved by the Regierung von Unterfranken, Würzburg. Mutagenesis was performed as described (44). DNA was prepared from tail clips using the DNeasy Tissue Kit (QIAGEN). For the chromosomal mapping, 45 genome-wide distributed discriminating microsatellite markers were analyzed on an ABI3700 device using the Genotyper 3.6 software. Further 86 SNPs and microsatellite markers were analyzed in a total of 386 backcross animals, resulting in a final mapping between the SNP marker Omp and microsatellite marker D7Mit220 on chromosome 7 (6.2 Mbp or $6 \mathrm{cM}$ ). Oligonucleotide sequences for analysis of public microsatellite markers were taken from the Broad Institute website and are available at the Jackson Laboratory (http://www.informatics.jax.org). Alternative primers were used for Omp (forward, 5'-TGATCTGACTGCTTTTCCAGGT; reverse, 5'-AGGATTCTGATGCTATGGGCTT) and Arfip2 (forward, 5'AGCAAGTAAGTGGCAAAGGA; reverse, 5'-AACTCCCTACCCCAAAACAC). For genotyping protocol genomic DNA was amplified and sequenced using 5'-CAAGAGATGGGTGAAGGTTG (forward) and 5'AAACGGAGACCTGTTCTGCT (reverse). All oligonucleotide primers were from MWG Biotech AG.

Flow cytometry and hematology. Monoclonal antibodies conjugated to FITC, PE, or allophycocyanin were from BD and Emfret Analytics. Cells were analyzed on a FACSCalibur (BD). For hematological analyses a Veterinary Animal Blood Counter was used (Scil Animal Care Company $\mathrm{GmbH}$ ). Platelet counts were adjusted using flow cytometry counts as calibration values.

Bone marrow transfer. Ly5.1 animals or Stim $1^{\text {Sax } /+}$ and age- and sex-matched WT animals were used as recipients or donors in reciprocal transfers. Stim $1^{\text {Sax } /+}$ and WT animals used for the transfer experiments were of mixed C3Heb/ $\mathrm{FeJ} \times \mathrm{C} 57 \mathrm{BL} / 6$ background and were tested to be homozygous for $\mathrm{H}-2^{\mathrm{b}}$ allele at the $\mathrm{H}-2$ locus and transplanted as described (45). Platelet counts and MPV was determined before and 4, 8 , and 12 weeks after the transfer. Serum-TPO was measured using a mouse ELISA kit (DuoSet mouse TPO, catalog no. DY488; R\&D Systems).

Processing of lymphoid tissues. Single cell suspensions from thymuses, lymph nodes, and spleens were prepared using a 70- $\mu \mathrm{m}$ nylon cell strainer (BD Falcon). Spleen cell suspensions were further subjected to hypoosmotic shock for red blood cell depletion. To obtain bone marrow cells, 1 femur of each animal was flushed with BSS and erythrocytes were lysed by incubation in TAC lysis buffer $(2.4 \mathrm{mg} / \mathrm{l}$ Tris, $8.3 \mathrm{~g} / \mathrm{l}$ ammonium chloride, $\mathrm{pH}$ 7.2) for 10 minutes at room temperature.

FACS analysis. The following monoclonal antibodies were used: antimouse CD4-PE, anti-mouse CD8 PE-Cy5, and anti-mouse CD3 FITC (all $\mathrm{BD}$ Biosciences - Pharmingen). Stainings were performed with $1 \times 10^{6}$ cells in $50 \mu \mathrm{PBS} / 0.1 \% \mathrm{BSA} / 0.02 \% \mathrm{NaN}_{3}$. Fc receptors were blocked by incubation with saturating amounts of supernatant of the $2.4 \mathrm{G} 2$ hybridoma. After the blocking step FITC- or PE-conjugated mAbs were added (15 minutes, $4{ }^{\circ} \mathrm{C}$ ). The cells were analyzed on either a FACScan or FACSCalibur flow cytometer using Cell Quest software (all BD). Dot plots and histograms are shown as $\log 10$ fluorescence intensities on a 4-decade scale.

Stainings of splenocytes. For staining of splenocytes, the following antibodies were used: anti-Gr1 FITC, anti-Mac1 PE, anti-CD3 Cy7, and antiB220 Alexa Fluor 647 (all from BD Biosciences - Pharmingen). B cells were from the $\mathrm{B} 220^{+} \mathrm{CD}^{-}$cell line, $\mathrm{T}$ cells from the $\mathrm{CD} 3^{+} \mathrm{B} 220^{-}$cell line, granulocytes from the $\mathrm{Gr} 1^{\mathrm{hi}} \mathrm{Mac} 1^{+}$cell line, and macrophages from the Mac $1^{\text {hi }} \mathrm{Gr} 1^{\text {lo }}$ cell line.

In vitro stimulation of spleen cell suspensions. Splenocytes were labeled with CFSE ( $5 \mu \mathrm{M}$; MoBiTec GmbH) and placed in a 24-well plate (Greiner BioOne $\mathrm{GmbH}$ ) with $2 \times 10^{6}$ cells in $2 \mathrm{ml}$ of RPMI medium (PAA) containing $10 \%$ heat-inactivated FCS, $1 \mathrm{mM}$ sodium pyruvate, nonessential amino acids, $100 \mathrm{U} / \mathrm{ml}$ each of penicillin and streptomycin, $30 \mu \mathrm{M}$ mercaptoethanol, and $2 \mathrm{mM} \mathrm{L}$-glutamine (all from Gibco). Anti-CD3 mAb (clone 1452C11; BD Biosciences - Pharmingen) was added at a final concentration of $0.1 \mu \mathrm{g} / \mathrm{ml}$. After 3 days cells were stained with anti-CD4 PE or anti-CD8 PE-Cy5 (BD Biosciences - Pharmingen) to determine CFSE-dye dilution among $\mathrm{CD}^{+}$and $\mathrm{CD}^{+}$cells, respectively.

$\mathrm{Ca}^{2+}$ measurement in primary $\mathrm{CD} 4^{+} \mathrm{T}$ cells. Lymph node cell suspensions $(n=3)$ from WT and Stim $1^{\text {Sax } /+}$ mice were incubated with $15 \mu \mathrm{l} / 5 \times 10^{6}$ cells of a mix of $25 \mu \mathrm{l}$ Indo-1 ( $2 \mathrm{mM}$ in DMSO; Molecular Probes), $25 \mu \mathrm{l}$ of Pluronic (Molecular Probes), and $113 \mu \mathrm{l} \mathrm{FCS} \mathrm{(GIBCO)} \mathrm{for} 45$ minutes at $37^{\circ} \mathrm{C}$. Subsequently, cells were stained with anti-B220 PE and antiCD8 PE. For T cell receptor complex stimulation, aliquots of cells were loaded with anti-CD3 mAb (clone 145-2C11; BD Biosciences - Pharmingen) at $10 \mu \mathrm{g} / \mathrm{ml}$ for 15 minutes on ice with $2 \times 10^{7}$ cells $/ \mathrm{ml}$. After extensive washing cells were resuspended in $\mathrm{Ca}^{2+}$-free Tyrode's buffer. Prior to the initiation of $\mathrm{Ca}^{2+}$ measurements, aliquots of $1 \times 10^{6}$ cells were diluted 1:20 with prewarmed $\mathrm{Ca}^{2+}$-free Tyrode's buffer and allowed to equilibrate for 5 minutes at $37^{\circ} \mathrm{C}$. Baseline $\mathrm{Ca}^{2+}$ levels were recorded for 50 seconds before $\mathrm{CaCl}_{2}(0.4 \mathrm{mM})$ was added. Bound anti-CD3 $\mathrm{mAb}$ was crosslinked by addition of goat anti-mouse Ig (Sigma-Aldrich) at $40 \mu \mathrm{g} / \mathrm{ml}$. TG was used at a final concentration of $5 \mu \mathrm{M}$. Data were acquired on a FACSDiva using CellQuest (both BD), and FlowJo (Tree Star) was used to calculate the kinetics of FL5/FL4 means (Gaussian smoothing) among CD8-B220- lymph node cells (>92\% CD4+ cells). FL5/FL4 ratios were determined under limiting as well as saturating conditions to calculate concentrations of free $\left[\mathrm{Ca}^{2+}\right]_{\mathrm{i}}(46)$.

Cytotoxic T cell function. Lymph node cells from WT or Stim $1^{\text {Sax } /+}$ mice (both $\mathrm{H}-2 \mathrm{k}$ ) were primed for 3 days against irradiated (20-Gy) C57BL/ 6 splenocytes $\left(\mathrm{H}-2^{\mathrm{b}}\right)$. Primed lymph node cells were used as effector cells at the indicated effector to target cell ratios against CFSE-labeled EL-4 cells $\left(\mathrm{H}-2^{\mathrm{b}}\right)$. After 20 hours, the number of AnnexinV- $\mathrm{PI}^{-}$target cells was determined by FACS using nonfluorescent beads (BD). Blocking anti-CD $8 \alpha \mathrm{mAb}$ (BD Biosciences - Pharmingen) was added at a final concentration of $20 \mu \mathrm{g} / \mathrm{ml}$.

KLH immunizations. WT or Stim $1^{\text {Sax/+ }}$ mice were immunized s.c. with an emulsion of $45 \mu \mathrm{l}$ PBS containing $25 \mu \mathrm{g}$ KLH (Sigma-Aldrich) and $15 \mu \mathrm{l}$ TiterMax (Alexis). After 4 weeks anti-KLH antibodies were detected in serum by ELISA and MACS-purified CD4 ${ }^{+} \mathrm{T}$ cells from peripheral lymph nodes were assayed in an in vitro recall assay using irradiated splenocytes as antigen-presenting cells and 10,1 , and $0.1 \mu \mathrm{g} / \mathrm{ml} \mathrm{KLH}$ for stimulation. Proliferation of $\mathrm{KLH}$-specific $\mathrm{T}$ cells was determined by measuring $3 \mathrm{H}$-thymidin incorporation for the last 18 hours of a 3-day culture.

Western blot analysis of Stim 1 expression in leukocyte subsets. B cells were purified from whole splenocytes by positive magnetic selection using anti-mouse IgG-biotin (Dianova) and streptavidin-conjugated MACS 
beads. Lymph node cells were used to purify $\mathrm{CD} 4^{+} \mathrm{T}$ cells by negative magnetic separation according to the manufacturer's instructions (Miltenyi Biotec). Purities of sorted T cells were greater than $96 \%$, and B cell purities were greater than $92 \%$. Whole cells were lysed using $1 \%$ NP-40. SDS-PAGE was used for protein separation followed by protein blotting onto a PVDF membrane. The anti-Stim 1 antibody was from Abnova Corporation (H00006786-M01).

Splenectomy. Mice were anesthetized with medetomidine, midazolam, and fentanyl. The spleen was identified from a left subcostal laparotomy and removed after appropriate blood vessel ligation. The wound was closed with 5-0 Prolene.

$\mathrm{Ca}^{2+}$ measurements in platelets. Washed platelets were incubated in $\mathrm{Ca}^{2+}-$ free Tyrode's buffer with $5 \mu \mathrm{M}$ Oregon Green Bapta-1-AM and $5 \mu \mathrm{M}$ FuraRed-AM (both from Molecular Probes) for 20 minutes at $37^{\circ} \mathrm{C}$. Platelets were resuspended in Tyrode's buffer containing either $2 \mathrm{mM}$ $\mathrm{Ca}^{2+}$ or 0.5 mM EGTA. Changes in $\left[\mathrm{Ca}^{2+}\right]_{\mathrm{i}}-$ as ratios of Oregon Green Bapta-1 fluorescence over FuraRed fluorescence - upon agonist-induced stimuli were real-time monitored and recorded on a FACSCalibur using CellQuest version 3.3 (BD). Data were analyzed offline by the shareware FCSPress. The system was calibrated for WT and Stim $1^{\operatorname{Sax} /+}$ platelets separately, and $\left[\mathrm{Ca}^{2+}\right]_{\mathrm{i}}$ was calculated from the fluorescent ratios as previously described (47).

Platelet life span experiments. Platelets were labeled in vivo with the intravenous injection of $5 \mu \mathrm{g}$ Alexa Fluor 488-conjugated anti-GPIX antibody $(2 \mu \mathrm{g}$ in the mutant) in $200 \mu \mathrm{l} \mathrm{PBS}$. Diluted whole blood $(50 \mu \mathrm{l})$ was incubated with $10 \mu \mathrm{l}$ PE-Cy5-conjugated anti-GPIb antibody for 10 minutes at room temperature. The Alexa Fluor 488-positive platelet population was determined as the percentage of the whole PE-Cy5-positive population by flow cytometry.

Bleeding time. A 3-mm segment of the tail tip was cut from anesthetized animals and the tail immersed into prewarmed PBS. Time until cessation of bleeding was measured or the experiment was interrupted after $15 \mathrm{~min}$ utes to prevent severe blood loss.

Aorta occlusion model. The abdominal cavity of anesthetized mice was longitudinally opened, and the abdominal aorta was prepared. An ultrasonic flow probe was placed around the aorta, and thrombosis was induced by one firm compression with a forceps. Blood flow was monitored until complete occlusion occurred; otherwise experiments were stopped manually after 40 minutes.
$\mathrm{FeCl}_{3}$ injury in mesenteric arterioles. Four- to five-week-old mice were anesthetized, and the mesentery was gently exteriorized through a midline abdominal incision. Arterioles (35-60 $\mu \mathrm{m}$ diameter) were visualized with a Zeiss Axiovert 200 inverted microscope $(\times 10)$ equipped with a 100 -watt $\mathrm{HBO}$ fluorescent lamp source and a charge-coupled device camera (CV-M300) connected to an S-VHS video recorder (AG-7355; Panasonic). Injury was induced by topical application of a $3-\mathrm{mm}^{2}$ filter paper tip saturated with $\mathrm{FeCl}_{3}(20 \%)$ for 10 seconds. Adhesion and aggregation of fluorescently labeled platelets in arterioles was monitored for 40 minutes or until complete occlusion occurred (blood flow stopped for longer than 1 minute).

TPO treatment. Hematological parameters were measured 1 day before and 5 days after beginning the TPO treatment. Animals received $2 \mu \mathrm{g}$ TPO s.c. once per day.

Statistics. Summarized results from at least 3 experiments per group are presented as mean \pm SD.Differences between WT and mutant groups were tested by 2 -tailed Student's $t$ test. Differences were considered significant if $P$ was less than 0.05 . Data on basal $\mathrm{Ca}^{2+}$ levels in T cells of WT and Stim $1^{\text {Sax } /+}$ mice were subjected to a 1 -tailed Student's $t$ test. $P<0.025$ was considered statistically significant.

\section{Acknowledgments}

We thank Karen Balbach, Nadine Pfeifer, Sandra Werner, and Christian Linden for help with cell sorting and $\mathrm{Ca}^{2+}$ measurements. This work was supported by the Rudolf Virchow Center and the Deutsche Forschungsgemeinschaft (grant SFB 688 to B. Nieswandt).

Received for publication April 4, 2007, and accepted in revised form August 15, 2007.

Address correspondence to: Bernhard Nieswandt, Rudolf Virchow Center, DFG Research Center for Experimental Biomedicine, University of Würzburg, Zinklesweg 10, 97078 Würzburg, Germany. Phone: 49-931-201-44060; Fax: 49-931-201-44068; E-mail: bernhard.nieswandt@virchow.uni-wuerzburg.de.

Johannes Grosse's present address is: Takeda Cambridge Ltd., Cambridge, United Kingdom.

Johannes Grosse and Attila Braun contributed equally to this work.
1. Berridge, M.J., Bootman, M.D., and Roderick, H.L. 2003. Calcium signalling: dynamics, homeostasis and remodelling. Nat. Rev. Mol. Cell Biol. 4:517529 .

2. Rosado, J.A., Redondo, P.C., Sage, S.O., Pariente, J.A., and Salido, G.M. 2005. Store-operated Ca2+ entry: vesicle fusion or reversible trafficking and de novo conformational coupling? J. Cell Physiol 205:262-269.

3. Roos, J., et al. 2005. STIM1, an essential and conserved component of store-operated $\mathrm{Ca} 2+$ channel function. J. Cell Biol. 169:435-445.

4. Liou, J., et al. 2005. STIM is a Ca2+ sensor essential for $\mathrm{Ca} 2+$-store-depletion-triggered $\mathrm{Ca} 2+$ influx. Curr. Biol. 15:1235-1241.

5. Zhang, S.L., et al. 2005. STIM1 is a Ca2+ sensor that activates CRAC channels and migrates from the $\mathrm{Ca} 2+$ store to the plasma membrane. Nature. 437:902-905.

6. Peinelt, C., et al. 2006. Amplification of CRAC current by STIM1 and CRACM1 (Orai1). Nat. Cell Biol. 8:771-773.

7. Mercer, J.C., et al. 2006. Large store-operated calcium selective currents due to co-expression of Orai1 or Orai2 with the intracellular calcium sensor, Stim1. J. Biol. Chem. 281:24979-24990.
8. Luik, R.M., Wu, M.M., Buchanan, J., and Lewis, R.S 2006. The elementary unit of store-operated Ca2+ entry: local activation of CRAC channels by STIM1 at ER-plasma membrane junctions. J. Cell Biol. 174:815-825

9. Feske, S., et al. 2006. A mutation in Orai1 causes immune deficiency by abrogating CRAC channel function. Nature. 441:179-185.

10. Vig, M., et al. 2006. CRACM1 is a plasma membrane protein essential for store-operated $\mathrm{Ca} 2+$ entry. Science. 312:1220-1223.

11. Prakriya, M., et al. 2006. Orai1 is an essential pore subunit of the CRAC channel. Nature. 443:230-233.

12. Yeromin, A.V., et al. 2006. Molecular identification of the CRAC channel by altered ion selectivity in a mutant of Orai. Nature. 443:226-229.

13. Huang, G.N., et al. 2006. STIM1 carboxyl-terminus activates native SOC, I(crac) and TRPC1 channels. Nat. Cell Biol. 8:1003-1010.

14. Lopez, J., Salido, G.M., Pariente, J.A., and Rosado, J.A. 2006. Interaction of STIM1 with endogenously expressed human canonical TRP1 upon depletion of intracellular Ca2+ stores. J. Biol. Chem. 281:28254-28264.

15. Ruggeri, Z.M. 2002. Platelets in atherothrombosis. Nat. Med. 8:1227-1234.
16. Nieswandt, B., and Watson, S.P. 2003. Platelet-collagen interaction: is GPVI the central receptor? Blood. 102:449-461.

17. Offermanns, S., Toombs, C.F., Hu, Y.H., and Simon, M.I. 1997. Defective platelet activation in G alpha(q)-deficient mice. Nature. 389:183-186.

18. Watson, S.P., et al. 2001. The role of ITAM- and ITIM-coupled receptors in platelet activation by collagen. Thromb. Haemost. 86:276-288.

19. Suzuki-Inoue, K., et al. 2006. A novel Syk-dependent mechanism of platelet activation by the C-type lectin receptor CLEC-2. Blood. 107:542-549.

20. Yu, P., et al. 2005. Autoimmunity and inflammation due to a gain-of-function mutation in phospholipase C gamma 2 that specifically increases external Ca2+ entry. Immunity. 22:451-465.

21. Dráber, P., and Dráberová, L. 2005. Lifting the fog in store-operated Ca2+ entry. Trends Immunol. 26:621-624.

22. Shivdasani, R.A., Fujiwara, Y., McDevitt, M.A., and Orkin, S.H. 1997. A lineage-selective knockout establishes the critical role of transcription factor GATA-1 in megakaryocyte growth and platelet development. EMBO J. 16:3965-3973.

23. Shivdasani, R.A., et al. 1995. Transcription factor NF-E2 is required for platelet formation indepen- 
dent of the actions of thrombopoietin/MGDF in megakaryocyte development. Cell. 81:695-704.

24. Ault, K.A., and Knowles, C. 1995. In vivo biotinylation demonstrates that reticulated platelets are the youngest platelets in circulation. Exp. Hematol. 23:996-1001.

25. Bergmeier, W., et al. 2003. Metalloproteinase inhibitors improve the recovery and hemostatic function of in vitro aged or injured mouse platelets. Blood. 102:4229-4235.

26. Bergmeier, W., et al. 2002. Flow cytometric detection of activated mouse integrin alphaIIbbeta3 with a novel monoclonal antibody. Cytometry. 48:80-86.

27. Nieswandt, B., et al. 2001. Evidence for cross-talk between glycoprotein VI and Gi-coupled receptors during collagen-induced platelet aggregation. Blood. 97:3829-3835.

28. Nieswandt, B., et al. 2001. Glycoprotein VI but not alpha2beta1 integrin is essential for platelet interaction with collagen. EMBO J. 20:2120-2130.

29. Gruner, S., et al. 2005. Relative antithrombotic effect of soluble GPVI dimer compared with antiGPVI antibodies in mice. Blood. 105:1492-1499.

30. Renne, T., et al. 2005. Defective thrombus formation in mice lacking coagulation factor XII. J. Exp. Med. 202:271-281.

31. Grafton, G., and Thwaite, L. 2001. Calcium chan- nels in lymphocytes. Immunology. 104:119-126.

32. Quintana, A. 1978. Effects of pimozide on the response of smooth muscle to non-dopamine agonists and calcium. Eur. J. Pharmacol. 53:113-116.

33. Soboloff, J., et al. 2006. STIM2 is an inhibitor of STIM1-mediated store-operated Ca2+ entry. Curr. Biol. 16:1465-1470.

34. Feng, J.M., et al. 2006. Golli protein negatively regulates store depletion-induced calcium influx in $\mathrm{T}$ cells. Immunity. 24:717-727.

35. Tu, H., et al. 2006. Presenilins form ER Ca2+ leak channels, a function disrupted by familial Alzheimer's disease-linked mutations. Cell. 126:981-993.

36. Bird, G.S., et al. 2004. Mechanisms of phospholipase C-regulated calcium entry. Curr. Mol. Med. 4:291-301.

37. Hassock, S.R., Zhu, M.X., Trost, C., Flockerzi, V., and Authi, K.S. 2002. Expression and role of TRPC proteins in human platelets: evidence that TRPC6 forms the store-independent calcium entry channel. Blood. 100:2801-2811.

38. Dellis, O., et al. 2006. Ca2+ entry through plasma membrane IP3 receptors. Science. 313:229-233.

39. El Daher, S.S., et al. 2000. Distinct localization and function of $(1,4,5) \operatorname{IP}(3)$ receptor subtypes and the $(1,3,4,5) \operatorname{IP}(4)$ receptor GAP1(IP4BP) in highly purified human platelet membranes. Blood. 95:3412-3422.
40. Holmes, A.M., Roderick, H.L., McDonald, F., and Bootman, M.D. 2007. Interaction between storeoperated and arachidonate-activated calcium entry. Cell Calcium. 41:1-12.

41. Rao, A.K., Jalagadugula, G., and Sun, L. 2004. Inherited defects in platelet signaling mechanisms. Semin. Thromb. Hemost. 30:525-535.

42. Ahmed, A., and Chang, C.C. 2006. Chronic idiopathic myelofibrosis: clinicopathologic features, pathogenesis, and prognosis. Arch. Pathol. Lab Med. 130:1133-1143.

43. Nicklas, W., et al. 2002. Recommendations for the health monitoring of rodent and rabbit colonies in breeding and experimental units. Lab. Anim. 36:20-42.

44. Augustin, M., et al. 2005. Efficient and fast targeted production of murine models based on ENU mutagenesis. Mamm. Genome 16:405-413.

45. Grosse, J., et al. 2006. Mutation of mouse Mayp/ Pstpip2 causes a macrophage autoinflammatory disease. Blood. 107:3350-3358.

46. Grynkiewicz, G., Poenie, M., and Tsien, R.Y. 1985. A new generation of $\mathrm{Ca} 2+$ indicators with greatly improved fluorescence properties. J. Biol. Chem. 260:3440-3450.

47. Nesbitt, W.S., et al. 2003. Intercellular calcium communication regulates platelet aggregation and thrombus growth. J. Cell Biol. 160:1151-1161. 